\title{
A Abordagem Psicológica da Problemática dos Desastres: Um Desafio Cognitivo e Profissional para a Psicologia
}

The Psychology approach on the issue of disasters: A challenge for the vocational and cognitive Psychology

Marcos Antônio Mattedi
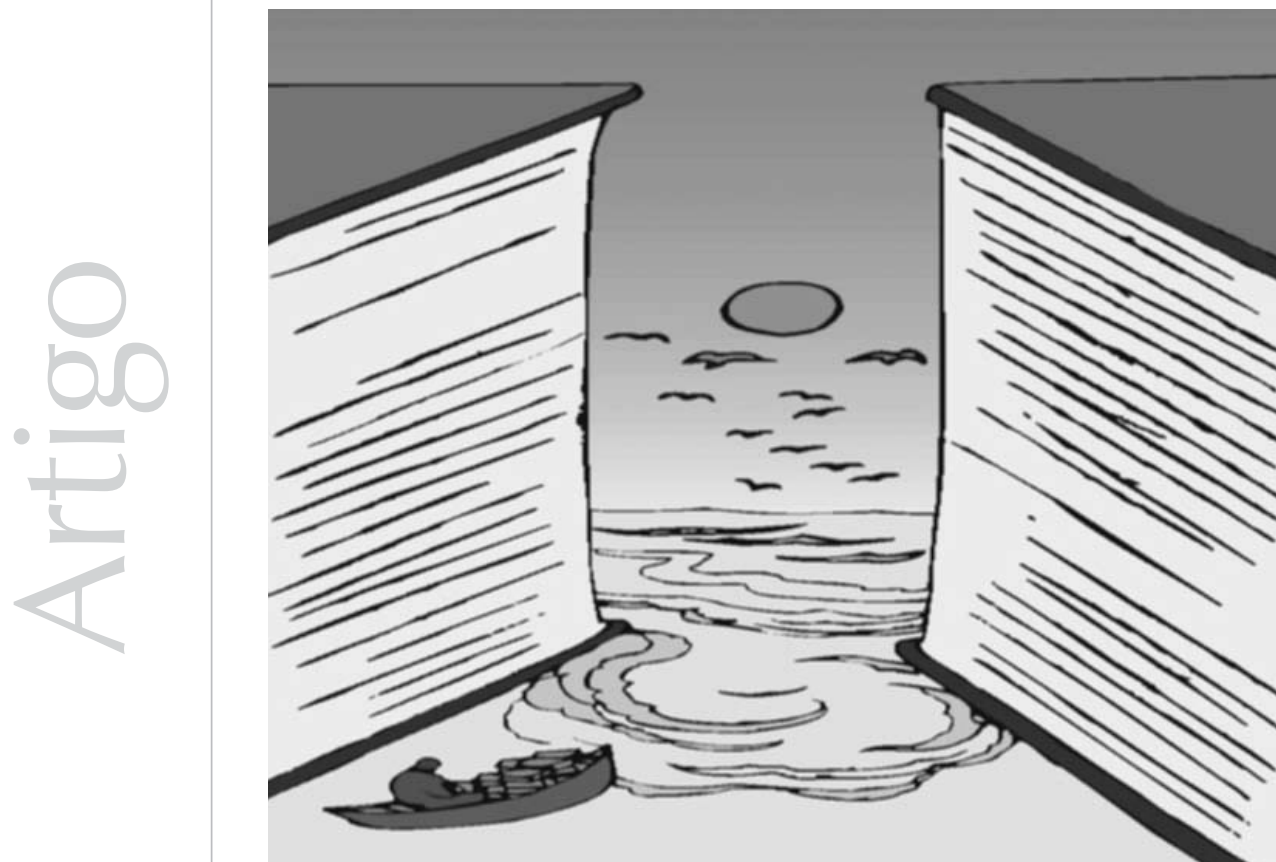
1Este trabalho foi preparado como uma contribuição para a mesa de trabalho As contribuições da Psicologia na construção de comunidades mais seguras:

Comportamento, cultura e organização, da

Reunião Internacional

por uma Formação Especializada em Psicologia da Emergência e dos Desastres, realizada em Brasília, de 08 a 10 de agosto de 2006

Resumo: O texto aborda o tema das contribuições da Psicologia para a construção de comunidades mais seguras ${ }^{1}$ e sustenta que a adequação das intervenções da Psicologia na produção da segurança constitui o resultado da forma como se configura a insegurança e de como as comunidades são dimensionadas. O desenvolvimento desse argumento baseia-se em dois procedimentos analíticos: o primeiro refere-se à apresentação das formas de caracterização da insegurança, considerando três tradições de pesquisa: os estudos de hazards, desastres e riscos, e o segundo diz respeito à apresentação das transformações que marcam o desenvolvimento da sociedade moderna nas últimas décadas. Com base nesses dois procedimentos, apresentaremos as contribuições da Psicologia para a construção de comunidades mais seguras, através da possibilidade de estabelecer uma Psicologia dos desastres no Brasil.

Palavras-chave: Psicologia. Comunidades. Segurança. Desastres.

\begin{abstract}
This article approaches the contributions of Psychology for the constructions of safer communities and it sustains that appropriate psychological interventions in the production of security are the result of the way Psychology represents insecurity and the way communities are structure. The development of this argument is based on two analytical procedures: the first consists on the presentation of the way insecurity is pictured, considering three research traditions: the hazards' studies, the disasters' studies and the risks' studies. The second refers to the presentation of the transformations that mark modern society development in the two last decades, in order to establish a psychology of disasters field of study in Brazil.
\end{abstract}

Keywords: Psychology. Communities. Security. Disasters.

Existem, evidentemente, muitas formas de examinar as contribuições da Psicologia na construção de comunidades mais seguras, através do comportamento, da cultura e da organização, por exemplo. A adequação da intervenção da Psicologia vai depender, contudo, da forma como configuramos as fontes de insegurança bem como da forma como dimensionamos as capacidades de resposta das comunidades. Assim, por um lado, verifica-se que as principais fontes de insegurança na sociedade moderna resultam da aplicação da ciência à tecnologia para a manipulação da natureza; por outro, como o desenvolvimento científico e tecnológico converteu-se num dos fatores de maior influência sobre a sociedade, ampliam-se progressivamente as demandas de informação para o monitoramento social da vulnerabilidade. Por isso, como assinala Ulrich Beck, na Sociedade do risco, a ciência se torna cada vez mais necessária, mas, ao mesmo tempo, sempre menos suficiente para a produção da segurança (Beck, 1996). A questão que resulta da relação entre essas duas dimensões não é menos paradoxal: como a Psicologia pode contribuir para produzir segurança, quando a ciência se converte na maior fonte reprodutora de insegurança?

Essa posição ambivalente não é uma propriedade específica da Psicologia, mas uma característica da integração progressiva da ciência à tecnologia. Essa integração constitui o resultado do seu potencial de gerar aplicação, principalmente no momento em que a produção do conhecimento se converte na principal fonte de inovação do processo produtivo. Isso significa que, à medida que a ciência se converte num setor produtivo, este passa a orientar cada vez mais a atividade científica. Verifica-se, assim, que a produção do conhecimento científico não pode ser separada de seu contexto de aplicação, porque a ciência mantém uma relação de "co-construção" com o contexto social: ao mesmo tempo em que são condições sociais específicas que permitem a produção do conhecimento científico, a aplicação tecnológica do conhecimento científico redefine o contexto social. Nesse sentido, para que possamos identificar e avaliar as contribuições da Psicologia para a construção de comunidades mais seguras, é necessário considerar a insegurança uma situação 
À medida que essa reflexividade do conhecimento científico se volta sobre a produção e a utilização do próprio

conhecimento cientifico, redefine-se também a imagem que a sociedade possui da ciência. que é, simultaneamente, manufaturada e confrontada tecnocientificamente.

À medida que essa reflexividade do conhecimento científico se volta sobre a produção e a utilização do próprio conhecimento cientifico, redefine-se também a imagem que a sociedade possui da ciência. Por um lado, verifica-se que é a própria aplicação do conhecimento científico que permite a manipulação massiva da natureza por meio do desenvolvimento tecnológico, e, com isso, torna-se cada vez mais evidente que a intensificação da freqüência e da magnitude provocados por acidentes aéreos, ferroviários, rodoviários, explosões industriais, rupturas de diques e também de inundações e secas são ativados pela forma como interagimos com a natureza. Por outro lado, a identificação, a avaliação e a confrontação desses desastres só podem ser expressas cientificamente, pois a difusão desse conhecimento especializado bloqueia a desconfiança dos sistemas especializados. Assim, do ponto de vista analítico, a sociedade em que vivemos é uma sociedade consciente de que a maior parte dos desastres que afetam as comunidades e os indivíduos são resultado do seu próprio desenvolvimento, na medida em que são causa e conseqüência dos padrões de desenvolvimento socioeconômicos predominantes (United Nations Development Program, 2004). Mais precisamente, vivemos numa sociedade que é consciente das ameaças que os desastres representam para a segurança das comunidades pela geração de conhecimento sistemático sobre as causas e conseqüências dos impactos, porém essa capacidade de autoconfrontação não é homogênea, e distribui-se de forma desigual socialmente. Freqüentemente, as populações mais carentes são as mais vulneráveis aos impactos dos desastres na medida em que existe um processo de institucionalização do risco: perdas provocadas por desastres são confrontadas por ações parciais que favorecem a ocupação de áreas de risco (Mattedi, 1999), o que é descrito como ciclo dos desastres: desastres-danos-reparaçãodesastre (Tobin \& Montz, 1997).
Para enfrentarmos essa questão, o primeiro passo envolve a apreciação das abordagens que tratam da insegurança. A maior parte dessas abordagens se funda numa espécie de divisão do trabalho epistemológico entre disciplinas que se ocupam da insegurança, ao estudar as dimensões naturais dos desastres, e disciplinas que se ocupam da insegurança, com a investigação das dimensões sociais. Por isso, a Psicologia precisa superar tanto as abordagens de corte geográfico que enfatizam a influência dos eventos sobre o comportamento quanto as abordagens de viés sociológico que enfatizam os impactos sobre o comportamento. A progressiva socialização da natureza por meio da tecnociência faz com que até fenômenos como, por exemplo, inundações e secas, que costumavam ser atribuídos a fatores externos à sociedade, passassem a ser vistos como resultado da mediação tecnocientífica da natureza pela sociedade. Assim, muito embora os desastres sejam freqüentemente percebidos, experienciados e descritos como "fenômenos anormais" ou "eventos desviantes", eles são ocorrências "normais" que resultam do grau de vulnerabilidade social das redes sociotécnicas que sustentam a vida moderna (Hilgartner, 2007).

Em seguida, a Psicologia precisa rever o que freqüentemente costumamos representar como comunidade. Devido à intensificação do processo de diferenciação social provocado pelo processo de individualização dos modos de vida, as comunidades e as regiões deixaram de ser "comunitárias". A insegurança não pode mais ser vista como uma característica específica de um grupo social, mas uma propriedade móvel que se manifesta de modo difuso. Na década de sessenta, por exemplo, o debate sobre a confrontação das enchentes na região do Vale do Itajaí opunha a visão dos especialistas técnicos à visão da comunidade; 20 anos depois, o debate sobre as enchentes é realizado por grupos sociais altamente diferenciados, que são capazes de se posicionar e de desenvolver argumentos não somente alternativos mas também construtivos. A comunidade deixa de ser 
vista como uma unidade uniforme e passiva, e converte-se numa entidade incerta que pode, ao mesmo tempo, reforçar e também enfraquecer a insegurança.

A consideração da contingência da segurança pressupõe a aplicação de uma noção que contemple tanto o caráter híbrido dos eventos como a variação difusa dos impactos. Assim, na primeira parte do texto, ocuparnos-emos de duas tarefas predominantes: a apresentação das diferenças e semelhanças entre os conceitos de desastres, hazards e riscos e a caracterização da noção de comunidade. Em seguida, trataremos mais detalhadamente da compreensão da forma como é produzido o conhecimento científico. O objetivo dessas duas operações é relacionar uma definição mais flexível da insegurança com uma visão mais ampla da atividade científica que possa basear a avaliação da contribuição da Psicologia para a construção de comunidades mais seguras.

\section{Compreendendo a insegurança}

A insegurança constitui sempre uma sensação muito difusa e resulta da ameaça de disrupção da rotina cotidiana de indivíduos ou comunidades; mais precisamente, a insegurança é o produto do perfil do risco na sociedade moderna (Giddens, 1991). No que se refere aos desastres e emergências, a bibliografia especializada é ampla e diversificada. Os primeiros estudos nessa área começaram a ser realizados no início do século passado, a respeito dos eventos que provocaram destruição massiva nos Estados Unidos. A intensificação das ocorrências nesse período despertou a atenção de diversas escolas disciplinares, como, por exemplo, a Sociologia, a Geografia, a Psicologia, a Ciência Política, a administração, etc. Cada uma dessas tradições disciplinares vai traduzir a especificidade dos eventos segundo as teorias e metodologias que lhes são próprias, levando, na maior parte dos casos, à criação de estudos ou conceitos teóricos dentro de uma própria tradição, mas também, muitas vezes, produzindo contatos interdisciplinares que geram novas perspectivas de abordagem. Essas tradições irão enfatizar mais certos aspectos em detrimento de outros, como, por exemplo, mais os fatores sociais em detrimento dos naturais, ou, ao contrário, mais os fatores naturais que os sociais. Hoje essa área de estudo constitui um campo de investigação consolidado e conta não somente com teorias e metodologias próprias, mas também com revistas, encontros, centros de pesquisa e formação. Do ponto de vista analítico, essas tradições podem ser distinguidas em três conjuntos principais, que são, ao mesmo tempo, opostos e complementares: hazards, desastres e riscos. Portanto, no que se refere à questão dos desastres, a compreensão da insegurança pressupõe a explicitação de dois aspectos analíticos relacionados à sua ocorrência: o primeiro diz respeito à classificação dos tipos de desastres, e o segundo compreende o que se pode entender como vida cotidiana ou rotina existencial.

Quando consideramos a questão da insegurança, podemos enfatizar a dimensão natural, mais precisamente, o agente desencadeador do evento. Nessa perspectiva, a insegurança pode ser descrita com base nos processos geofísicos que cercam o mundo humano; o fator determinante da caracterização dos desastres, portanto, compreende a dimensão física. A insegurança é determinada, classificada e ordenada de acordo com os diversos agentes desencadeadores: meteorologia (furacões, inundações, avalanches, nevascas), geológicos (terremotos, vulcões e deslizamentos) e hidrológicos (inundações, secas e incêndios). Com base nesses pressupostos, desenvolveuse uma classificação que compreende: a) mecanismos físicos (magnitude, duração, extensão espacial); b) distribuição temporal (freqüência, sazonalidade, parâmetros diversos); c) distribuição espacial (localização geográfica); d) dinâmica de eclosão (rapidez de início, rapidez de término). Cada um desses aspectos tem sido exaustivamente pesquisado, pois acredita-se que, reconhecendo as 
diferentes magnitudes, freqüências e durações dos eventos, pode-se entender melhor $\mathrm{o}$ comportamento humano frente aos desastres e, dessa forma, estabelecer procedimentos de predição, proteção e resposta. Argumenta-se, por exemplo, que, quando o intervalo de ocorrência de um evento for relativamente certo (alta freqüência), verificam-se estudos constantes de busca de respostas, enquanto eventos caracterizados por um longo período de retorno (baixa probabilidade) apresentam mediações esporádicas. Acredita-se, assim, que esse processo gere padrões de eventoresposta específicos: comunidades que convivem com eventos de alta freqüência apresentam uma tendência de respostas mais sistemáticas e, com isso, menor vulnerabilidade social, ou seja, acabam desenvolvendo um aprendizado social que inclui dispositivos psicológicos de convívio com os fenômenos. Portanto, a segurança de uma comunidade constitui o resultado da experiência e aprendizado acumulados no convívio com o evento.

Desde os anos 70, a insegurança passou a ser vista como o produto da interação de forças físicas e humanas, pois o caráter ameaçador de um evento só pode ser avaliado, ou melhor, só pode ser precisamente dimensionado levando-se em conta um sistema social determinado. Nesse sentido, os desastres passaram a ser considerados como o ponto da interação entre fatores físicos que interagem com a realidade cultural, política e econômica da sociedade. Esse deslocamento do foco revigorou o enquadramento metodológico da abordagem para os fatores que determinam o ajustamento humano. Nessa linha de pesquisa, existe um número verdadeiramente extenso de modelos técnicos desenvolvidos para caracterizar o comportamento dos indivíduos antes, durante e depois da ocorrência de um evento. Esses modelos variam em função da ênfase contida nos fatores cognitivos (variações psicológicas e características atitudinais) ou nos fatores situacionais (sistema social). Esquemas analíticos behaviorista, utilitarista, marxista, etc, são utilizados para caracterizar a percepção da vulnerabilidade e o processo de vitimização por meio de quatro tipos principais de comportamento: 1) absorção passiva dos impactos: reflete a inexistência de consciência do risco, o que dificulta a preparação e aumenta a vulnerabilidade; 2) ajustamento temporário: absorção dos impactos por meio da solidariedade comunitária e aceitação dos riscos pela população; 3) redução dos impactos: desenvolvimento de estratégias de atenuação individual antes, durante e depois dos impactos, o que exprime a capacidade da comunidade de estimar os custos de proteção e as perdas; 4) modificação radical do comportamento: ocupação do espaço e redefinição do modo de vida, que indicam a disposição política privativa de longo prazo.

A preocupação sistemática com a relação entre os fatores pré, trans e pós-impacto deslocou o foco de abordagem para a relação que se estabelece entre a organização social e o comportamento individual. Nesse sentido, argumenta-se que a insegurança é resultado da relação de continuidade entre as condições sociais pré-impacto e a situação pós-impacto. Não se pode tratar separadamente a situação de emergência da situação pré-impacto: desastres constituem, primariamente, um fenômeno social, e, portanto, deveriam ser identificados em termos sociais. Trata-se, portanto, de caracterizar as especificidades da unidade social impactada e os padrões de resposta compreendidos. Assim, por exemplo, no tempo-1, pré-impacto, destacam-se ações de preparação e reação; no tempo-2, pós-impacto, as medidas de recuperação e mitigação. Assim, o comportamento frente aos desastres vai depender dos tipos de integração e conflito observados na comunidade e da experiência acumulada na confrontação da crise. Nesse sentido, um desastre pode ser caracterizado nos seguintes termos: quanto aos eventos, eles podem ser diferenciados por sua energia (física), sua periodicidade (temporal) e sua declaração formal como desastre (social); os impactos podem ser distinguidos em termos de seus danos ao ambiente natural ou humano (físico), duração (temporal) e grau de disrupção da rotina de funcionamento (social); a unidade social varia 
A teoria cultural do risco está associada à pesquisa desenvolvida pela antropóloga Mary Douglas, e sustenta o caráter social de todas as noções de risco, o que leva à diluição de sua genealogia. pela localização (física), o tempo de convívio com o evento (temporal) e o nível societal (social); as respostas envolvem a modificação do ambiente natural construído (física), implementadas antes, durante ou depois da ocorrência (temporal), que resultam de uma variedade de processos institucionais e não institucionais (social) (Kreps, 1989). Essa proposta suscitou uma série de controvérsias que ilustram bem os desafios de definição do campo de estudo, do ponto de vista sociológico (Bailey, 1989; Drabeck, 1989; Turner, 1989).

Nos últimos anos, observa-se uma inversão dessa postura metodológica, e, com isso, a ênfase do estudo da insegurança deslocouse para os efeitos negativos dos impactos provocados pelo sistema humano no meio ambiente. A disseminação desses parâmetros acabou despertando o interesse das ciências sociais em geral e da Sociologia, Antropologia e Psicologia sobre as dimensões sociais, culturais e subjetivas do risco em particular, o que gerou profundos questionamentos sobre o efetivo grau de generalidade desses estudos qualitativos. Esse questionamento sociocognitivo pode ser ilustrado pela referência ao que se convencionou chamar de teoria cultural do risco e pela teoria sociedade do risco. A teoria cultural do risco está associada à pesquisa desenvolvida pela antropóloga Mary Douglas, e sustenta o caráter social de todas as noções de risco, o que leva à diluição de sua genealogia. Segundo a autora, escolhendo um modo da vida, optamos por conviver entre semelhantes, pois uma forma de vida possui seu próprio portfólio de riscos. Afinal, em seu ponto de vista, partilhar idênticos valores e constitui, da mesma forma, inversamente, partilhar os mesmos riscos (Douglas \& Wildasky, 1984). No mesmo período, paralelamente, para o sociólogo Ulrich Beck a questão do risco está associada à tendência de agravamento do grau de destruição do desenvolvimento tecnológico e aos impactos ambientais, e o autor ressalta que, na verdade, inexiste uma transformação mais profunda da sociedade moderna. Os riscos emergem como um produto do próprio desenvolvimento científico e tecnológico moderno, ou seja, o perigo é manufaturado a partir do desenvolvimento socioeconômico que caracteriza a "sociedade de risco" (Beck, 1996); com o "envelhecimento da modernidade", a produção da riqueza vem acompanhada da construção do risco.

Contudo, a intensificação da freqüência e da magnitude dos impactos vem redefinindo nossa relação com a segurança. As características principais das fontes de insegurança contemporâneas são: 1) a invisibilidade cotidiana das causas, pois os pontos de impactos não estão mais diretamente ligados aos seus pontos de origem; 2) a escala autodestrutiva, que assume uma dimensão global; 3) as fontes não se encontram mais confinadas a um tipo de sociedade e a determinados grupos sociais. Esse contexto social que se concretiza pelo processo da incerteza, da ameaça e da insegurança tem sido definido como sociedade de risco. Para Beck, uma sociedade que concebe a si mesma como uma sociedade do risco constitui uma sociedade que se encontra num processo de "modernização reflexiva". A modernização compreende, analiticamente, um estágio de desenvolvimento no qual a sociedade passa a se ocupar com os problemas que o seu próprio desenvolvimento acaba provocando. Esse processo compreende duas fases predominantes: 1) a primeira refere-se a um estágio em que os efeitos e as auto-ameaças são sistematicamente produzidos, porém, ainda não são questões públicas; 2 ) a segunda diz respeito à conversão desses problemas em questões políticas, ou seja, a dinâmica de desenvolvimento da sociedade se torna publicamente problemática; mais precisamente, a modernização reflexiva constitui um efeito do aumento do conhecimento e da ciência sobre os efeitos da própria modernização social. Com o aumento da importância do conhecimento, cresce também a importância daqueles que produzem, interpretam e divulgam conhecimentos.

Com base nessas considerações, podemos verificar que a insegurança constitui uma 
propriedade qualitativa dos desastres. Assim, podemos observar que a avaliação da contribuição da Psicologia para a construção de comunidades mais seguras envolve, inicialmente, a caracterização dos fatores que as ameaçam. Do ponto de vista analítico, temos à disposição três abordagens predominantes, das quais podemos derivar elementos analíticos para caracterizar a insegurança: 1) podemos configurar a insegurança com base nos estudos de hazards e enfocar a ameaça representada pela ocorrência dos eventos desencadeadores dos desastres; 2) podemos nos concentrar nos impactos segundo a tradição dos estudos de desastres; 3) podemos pensar as potencialidades em termos de estudo de risco. Cada uma dessas caracterizações pressupõe um tipo específico de intervenção e de confrontação.

\section{Reconfigurando comunidades}

Uma das características mais marcantes da atualidade compreende a instabilidade e a proliferação da incerteza. É por isso que noções como desastres, hazards e riscos se tornam centrais para entender nossa época. Podemos considerar todo o conjunto de informações produzidas e sistematizadas nos estudos sobre desastres, hazards e riscos como uma espécie de introspecção que a sociedade efetua sobre o sentido do seu desenvolvimento com o propósito de criar mecanismos que nos permitam conviver com os riscos, ou, mais precisamente, nos permitam desenvolver dispositivos materiais e subjetivos para confrontar os desastres. As formas como os desastres foram sendo representados e enfrentados historicamente constituem um indicador por meio do qual podemos explicar o crescente interesse pelo tema da (in)segurança na atualidade. Nas sociedades pré-industriais, por exemplo, o risco tomava a forma de perigos naturais: tremores de terras, erupções vulcânicas, inundações, secas, etc. Esses desastres não foram criados intencionalmente, e seus impactos são espacialmente localizados e são culturalmente atribuídos a forças externas à sociedade. Com o surgimento da sociedade industrial, as origens, conseqüências e características dos desastres mudaram. A forma como os riscos de ocorrência são entendidos e as reações a eles também mudam, passando a depender de indivíduos e forças sociais. Na sociedade industrial, a culpa ou a responsabilidade pelas ameaças pode ser identificada, e suas probabilidades podem ser calculadas em termos estatísticos.

Comunidades podem ser definidas como redes de tradução sociotécnicas que estabilizam as associações simbólicas e materiais, mantendo unidos os elementos que compõem o mundo social e os elementos que compõem o mundo natural. Esses dispositivos sociotécnicos podem ser muito variados, como, por exemplo, leis, equipamentos, sistemas de comunicação, energia ou alimentação, vias de transporte, acervos artísticos, etc., mas podem também assumir diversos significados, criando as condições por meio das quais os indivíduos representam e manipulam, ou em outros termos, constroem e reconstroem o mundo em que vivem. Contudo, apesar de as comunidades serem formadas por atores, elas não podem ser consideradas como um simples agrupamento das ações e percepções individuais, porque cada ator constitui, ao mesmo tempo, um ator e uma rede que cria e recria sua própria estabilidade. Assim, embora uma comunidade possa reconhecer o grau de vulnerabilidade de sua rede de sustentação em termos dos fatores de risco e variações sociais e espaciais dos eventuais impactos e, além disso, identificar estratégias de proteção, nem sempre essas medidas podem ser compreendidas e implementadas, porque dependem das condições por meio das quais cada ator traduz o problema. A combinação específica de cada rede gera constrangimentos e oportunidades contínuos de resposta e ajustamento, e, com isso, cada modificação afeta, ao mesmo tempo, os atores e as redes que ele próprios formam.

Como cada comunidade é composta por entidades que atuam, simultaneamente, tanto como atores quanto como redes, as 
identidades desses atores-redes são móveis. Para coordenar suas ações, cada ator-rede põe em operação estratégias de simplificação e de justaposição de papéis. Assim, por exemplo, do ponto de vista de uma comunidade, o corpo de bombeiros constitui, ao mesmo tempo, um ator que se relaciona com outros atores, como são os casos dos hospitais, da polícia militar, da defesa civil, da prefeitura, das indústrias, dos moradores de um bairro, etc., mas também é uma rede que pode ser formada por outros atores. Portanto, o papel que o corpo de bombeiros desempenha na manutenção da rede sociotécnica de associação do natural e social tende a variar segundo o tipo de ator considerado. Para a prefeitura e o hospital da comunidade, ele pode assumir o papel de apoio ao resgate de pessoas, mas, para os moradores do bairro, pode assumir outro, e assim por diante, mas a prefeitura, o hospital e os moradores também possuem significados distintos para o próprio corpo de bombeiros, e esperam que ele execute tarefas que reforcem suas posições na rede. Portanto, uma comunidade constitui, simultaneamente, um ator cuja atividade consiste em entrelaçar elementos heterogêneos e uma rede que seja capaz de transformar os atores que a compõem.

Comunidades que são formadas por redes diferentes não somente estabilizam a associação entre o natural e o social de forma diferente, mas se autodefinem de forma diferente. As comunidades distinguemse tanto pelo tipo de atores que compõem a rede quanto pelo padrão de relações que estabelecem entre si. Esse padrão constitui o resultado da forma como cada ator traduz e se converte em porta-voz de outras entidades. Quanto mais interesses são mobilizados em torno da atuação de um ator, mais decisivo ele se torna na manutenção da rede, reduzindo a complexidade e tornandose um ponto de passagem obrigatório para os demais atores. Os papéis e a identidade que um ator atribui ao outro podem ser questionados, problematizados ou negados, o que gera divergências que redefinem a posição de cada ator na rede. Assim, por exemplo, um ator-rede como o corpo de bombeiros, que havia se convertido num ponto de passagem obrigatório para outros atores, pode ser forçado a cruzar os pontos de passagem que foram estabelecidos por outros atores para a manutenção da segurança. Portanto, as comunidades diferem porque as redes são móveis e heterogêneas.

Com a aplicação da noção de rede para a caracterização das comunidades, podemos reconfigurar a questão da segurança. Desse ponto de vista, um desastre representa uma desestabilização da rede sociotécnica por meio da ruptura da associação cognitiva e material que mantinha unidas as dimensões social e natural. A desestabilização dessa rede de processamento tecnocientífico quebra o suporte psicossocial que permite aos indivíduos assegurarem o monitoramento e a manutenção simbólica e material da existência. Assim, a insegurança pode ser considerada uma função do grau de confiança na estabilidade da rede que mantém unidos os elementos sociais e naturais. Por exemplo, a ocupação do leito secundário de um rio estabelece uma associação entre o natural e social, porém a ocorrência de uma inundação redefine os termos como os indivíduos e a comunidade traduzem as dimensões natural e social na rede sociotécnica. Assim, passam a ser problematizadas a forma como o natural foi associado ao social e a forma como o social é associado a natural, por meio de uma tradução tecnocientífica baseada em enunciados científicos e de artefatos tecnológicos que estabilizam a vida do indivíduo naquela região.

O comportamento e o estado mental dos indivíduos em situações de emergência variam segundo a consistência da rede. Isso significa que a capacidade de reação e processamento vai depender da capacidade de avaliar a consistência da rede, o que envolve, entre outros fatores, a percepção dos pontos de instabilidade da rede, o nível de preparação, a habilidade para conviver com a incerteza e experiência prévia. Em outras palavras, o comportamento constitui o 
Portanto, a diferença entre os atores que conseguem absorver os impactos de dissolução da rede e os atores para os quais a dissolução da rede se revela traumática está associado ao grau de suspeita que eles nutrem a respeito da estabilidade da rede. resultado de como cada comunidade percebe e administra as ameaças de desestabilização da rede, ou das estratégias de adaptação psicológica. Portanto, quanto mais uma comunidade suspeita da estabilidade de sua própria rede, menor o impacto gerado pela desarticulação da rede. Assim, as comunidades se diferenciam não pela capacidade de absorção dos impactos, mas pelo grau de desconfiança que conseguem alimentar a respeito dos dispositivos que mantêm unidos o mundo social e o mundo natural. Falar assim de percepção, preparação e prevenção compreende tornar os membros constituintes da rede conscientes da instabilidade das associações que eles mesmos produzem e reproduzem. Portanto, a diferença entre os atores que conseguem absorver os impactos de dissolução da rede e os atores para os quais a dissolução da rede se revela traumática está associado ao grau de suspeita que eles nutrem a respeito da estabilidade da rede. Quanto mais um ator se mostra aderente à rede sociotécnica, mais vulnerável ele se encontra no caso de desestabilização da rede.

Tomando como referência a noção de comunidade desenvolvida anteriormente, um desastre pode ser definido pelo grau de desestabilização da rede sociotécnica de associação simbólica e material dos elementos do mundo social e do mundo natural. Nesse sentido, a segurança constitui o produto da percepção do grau de consistência da rede, ou seja, quanto menos densa a rede, mais problemático se torna o processamento do desastre. Isso significa que, quanto mais estável uma rede, menos ameaçada se torna uma comunidade, ou seja, quanto mais uma comunidade se conhece, mais ela consegue gerir as ameaças. Nesse sentido, a tarefa da Psicologia para a construção de comunidades mais seguras constitui não somente explicar e intervir nos efeitos que a desestabilização provoca no comportamento individual ou na condição mental dos indivíduos, mas, sobretudo, revelar os mecanismos por meio dos quais os indivíduos estão deridos as redes sociotécnicas. Mais precisamente, a contribuição da Psicologia para a construção de comunidades mais seguras consiste, por um lado, na realização de pesquisas sobre o comportamento individual nos períodos pré, trans e pós-impactos, e, por outro, na capacidade de preparação e recuperação de comunidades impactadas.

\section{Vivendo na insegurança, agindo nos desastres}

O que podemos notar, considerando a questão dos desastres à luz das transformações que marcaram a sociedade ocidental nas últimas décadas, é que a sensação de insegurança não constitui um fato isolado e não está associada somente à questão dos desastres. Na verdade, uma das características mais marcantes da atualidade compreende justamente a instabilidade e a proliferação da incerteza. Afinal, como explicar a relação ambivalente entre o aumento progressivo de recursos investidos em medidas de monitoramento dos desastres e, ao mesmo tempo, uma intensificação da destruição provocada pelos impactos? Como explicar o fato de que, mesmo durante o Decênio Internacional para a Redução de Desastres Naturais - Bulding a Culture of Prevention, declarado pelas Nações Unidas para o período de 19902000 (trata-se de uma declaração da ONU sem referência específica) com o objetivo de fortalecer as habilidades científicas e tecnológicas de confrontação, a humanidade tenha testemunhado os desastres mais dramáticos e custosos de sua história? Essa ambivalência revela as múltiplas dimensões do processo de construção do risco, como, por exemplo, a importância desempenhada pela deterioração ambiental e o aumento da pobreza observado nesse período. Tal fato demonstra que o agravamento dos problemas dos desastres nas últimas décadas está intimamente relacionado aos processos de desenvolvimento socioeconômico. Assim, podemos considerar todo o conjunto de informações produzidas e sistematizadas nos estudos sobre desastres, hazards e riscos como uma espécie de introspecção que a sociedade efetua sobre o sentido do seu desenvolvimento com o propósito de criar 
mecanismos que permitam conviver com os riscos, ou, mais precisamente, permitam desenvolver dispositivos para confrontar os desastres. As contribuições da Psicologia para a construção de comunidades mais seguras dependem muito do modelo por meio do qual se desenvolve a questão da segurança das comunidades.

\section{A produção do conhecimento}

A primeira e mais importante contribuição da Psicologia para a construção de comunidades mais seguras consiste, evidentemente, na produção de conhecimento autocrítico, mais precisamente, o estabelecimento dentro dessa disciplina de uma subcomunidade de especialistas que sejam capazes não somente de compartilhar as mesmas técnicas, os mesmos saberes incorporados e que sejam capazes de comparar experimentos, de avaliar e capitalizar os resultados, mas, sobretudo, de reconhecer o caráter ambivalente do conhecimento científico. Esse processo envolve a compreensão dos mecanismos de tradução disciplinar dos desastres e das situações de emergência: 1) como cada desastre é único, a operação tem início com a redução da diversidade e complexidade do mundo pela transposição do fenômeno ao laboratório, o que permite produzir equivalência entre os casos; 2) segue pela constituição de um grupo de pesquisa que, com o apoio de competências e instrumentos, explica o desastre simplificado em termos de comportamento individual e condição mental frente à crise; 3) finaliza com o retorno ao mundo dos conhecimentos e técnicas produzidas no laboratório, fornecendo alianças com o mundo. Portanto, falar das contribuições da Psicologia para a construção de comunidades mais seguras envolve, inicialmente, um acompanhamento dessa operação.

Como os estudos de desastres constituem uma área de pesquisa consolidada internacionalmente e já existe o desenvolvimento de uma "psicologia dos desastres", que investiga o comportamento dos indivíduos e suas disposições mentais em situações de vulnerabilidade e desastres, talvez o maior desafio consista na integração desse tipo de preocupação nos processo de formação e atuação profissional. Nesse sentido, a principal contribuição da Psicologia para a construção de comunidades mais seguras é tornar as comunidades mais conscientes da insegurança da rede sociotécnica; afinal, quanto maior a desconfiança de uma comunidade em sua rede de sustentação, maior desenvolvimento de dispositivos de segurança. Isso pressupõe uma "psicologia reflexiva", um tipo de investigação que parta do exame das contribuições da própria Psicologia para a produção da insegurança. Assim, ao mesmo tempo em que o conhecimento produzido pela Psicologia se converte numa ferramenta para adequar as ações de preparação e recuperação, os desastres se transformam num "laboratório privilegiado", que permite à Psicologia avaliar os próprios limites dos instrumentos, técnicas e teorias que são aplicados. A progressiva aplicação da Psicologia aos desastres contribuiu, por exemplo, para desmistificar a imagem freqüentemente veiculada pelos meios de comunicação de massa de que as situações de emergência se caracterizam pela desintegração física, e são acompanhadas da desintegração mental e moral das comunidades. A pesquisa em psicologia dos desastres tem mostrado que comportamento das vítimas e dos indivíduos atingidos por desastres não pode ser reduzido a ações anômicas, como, por exemplo, pânico, comportamento irracional e antisocial ou crimes. As vítimas não são seres incapazes que dependem passivamente da ajuda externa e que se encontram sem condições de administrar as condições de subsistência. $\mathrm{Na}$ maior parte dos casos, as pessoas demonstram muita habilidade para enfrentar os problemas gerados pela redefinição da rede sociotécnica e para encontrar alternativas de atuação na situação. A desarticulação de uma rede é acompanhada ou substituída pelo surgimento de uma rede emergente que redefine as formas de significação e manipulação da subsistência. A pesquisa em Psicologia mostra que a desestabilização da rede sociotécnica 
O desastre ensina que toda rede sociotécnica é provisória, contingente, e que as redes que sustentam a vida de uma comunidade são continuamente construídas e reconstruídas; mais precisamente, que o mundo no qual vivemos não é conhecido e nem controlável, o que nos torna conscientes de nossa vulnerabilidade. de mediação, ou seja, a perda da rede de mediação não converte os indivíduos de Dr. Jekill em Mr. Hyde.

\section{Aplicação do conhecimento}

Com a produção desse tipo de informação, a Psicologia pode mostrar que comunidades não são receptores passivos de impactos negativos, mas redes dinâmicas capazes de aprendizado. O desastre ensina que toda rede sociotécnica é provisória, contingente, e que as redes que sustentam a vida de uma comunidade são continuamente construídas e reconstruídas; mais precisamente, que o mundo no qual vivemos não é conhecido e nem controlável, o que nos torna conscientes de nossa vulnerabilidade. Assim, todas as práticas de preparação pré-impacto pressupõem que os indivíduos se adaptem ou concordem com os planos e programas de proteção. Por exemplo, um plano de proteção que requer uma mudança drástica da rotina cotidiana ou do comportamento típico dos grupos ou membros de uma comunidade apresenta muita resistência. $\mathrm{O}$ grau de adequação do plano vai depender da adequação do comportamento cotidiano ao comportamento típico em situações de emergência. Mais precisamente, os planos precisam se ajustar às pessoas, e não as pessoas aos planos. Por outro lado, esse plano não precisa ser formalizado, mas incorporado na prática cotidiana da comunidade. Nesse sentido, a Psicologia pode auxiliar na diminuição das decalagens entre as características técnicas das medidas de proteção e a percepção do risco da comunidade. Dessa forma, a segurança depende da confiança na estabilidade da rede.

Uma das questões mais importantes na confrontação dos desastres diz respeito aos consensos e conflitos que surgem nas situações de emergência quanto aos padrões ou à dinâmica de reestabilização da rede. Situações de emergência costumam desencadear um alto grau de flexibilidade associativa das instituições comunitárias, que favorece o reconhecimento mútuo e a integração social. Assim, durante e imediatamente após os impactos, as relações sociais costumam caracterizar-se por um alto nível de solidariedade e cooperação, porém, com o passar do tempo e a reconstituição da rede, costumam emergir novas e antigas clivagens sociais na comunidade a respeito da pertinência e da adequação da assistência. Nesse sentido, uma segunda contribuição da Psicologia para a construção de comunidades mais seguras consiste na produção de informações e no desenvolvimento de técnicas de intervenção que permitam administrar os mecanismos que favorecem ou bloqueiam a formação de comportamentos cooperativos e competitivos no processo de reconstrução da rede.

Do ponto de vista prático, a melhor forma de aplicar o conhecimento da Psicologia no processo de confrontação de situações de desastre consiste em integrar esse tipo de informação no Programa de Saúde da Família. Esse programa é formado por uma equipe de especialistas que permite a integração da questão dos desastres e das situações de emergência. A vulnerabilidade das condições de moradia constitui um fator decisivo não somente para as condições materiais de vida mas também para a avaliação subjetiva da qualidade de vida. Pode, por exemplo, regionalizar a tematização das fontes mais freqüentes de desestabilização da rede ou de insegurança de cada família, fazendo com que a percepção das famílias sobre questões como enchentes, secas, deslizamentos e queimadas se converta em indicadores da percepção subjetiva da qualidade de vida das pessoas. Esse tipo de intervenção da Psicologia permite que os indivíduos se tornem mais reflexivos, ou melhor, permite que os indivíduos ampliem as condições de monitoramento das fontes de insegurança de sua rede de subsistência.

Desastres assustam, mas também fascinam, porque revelam o quanto a existência humana é precária e frágil. Os desastres rompem a capacidade da rede sociotécnica de manutenção da vida e também a capacidade de processamento da experiência de morte. Esta foi seqüestrada pela operação de instituições especializadas como, por exemplo, os sistemas médico e mercantil, que afastam a morte do cotidiano e impedem que a morte afete a rotina produtiva dos indivíduos. Um desastre desarticula essa forma de processamento e impõe às pessoas o processamento direto da perda e da morte. A 
Psicologia descobriu isso, e os psicólogos não se cansam de repetir: as pessoas são diferentes, e pessoas diferentes reagem de forma diferente. Em síntese, as contribuições da Psicologia para a construção de comunidades mais seguras estão relacionadas à matriz analítica por meio da qual configuramos não só a insegurança e os desastres, mas também a segurança e a comunidade. Por um lado, se tomarmos uma matriz epistemológica realista, os desastres se transformam analiticamente numa ameaça para a comunidade em função de sua magnitude e freqüência, e os impactos constituem o produto da capacidade de processamento social do problema. Essa caracterização é o resultado da combinação de uma configuração do problema que separa as dimensões humanas (social) e não-humanas do problema (natural), com uma representação estrutural-funcionalista de comunidade como organização/resposta. Na divisão do trabalho disciplinar, a Psicologia vai ocupar um papel específico, que consiste em compreender e intervir sobre os efeitos que a eclosão de um desastre exerce sobre o comportamento individual e sobre as condições subjetivas dos indivíduos afetados pelo desastre. Nesse sentido, a intervenção da Psicologia consiste em produzir e aplicar conhecimentos que possam ser utilizados para cuidar dos efeitos negativos que a disrupção da vida cotidiana desencadeia sobre o comportamento individual e o estado mental dos indivíduos que são afetados direta ou indiretamente. Por outro lado, a adoção de uma matriz epistemológica construtivista converte e reposiciona analiticamente a tarefa da Psicologia na construção de comunidades mais seguras. O sentido desse tipo de intervenção visa, por um lado, a evitar a disrupção e a estimular a recomposição do padrão de vida pré-impacto, porém isso, é claro, depende muito da plataforma epistemológica por meio do qual a Psicologia define a si mesma.

\section{Marcos Antônio Mattedi}

Doutor em Ciências Sociais, professor titular do Mestrado em desenvolvimento Regional da Fundação Universidade Regional de Blumenau.

E-mail:mam@furb.br

Endereço para correspondência:

Rua Antônio da Veiga, no 140 - Itoupava Cep: 89012-900, Blumenau-SC

Recebido 17/04/07 Reformulado 05/09/07 Aprovado 20/09/07

Referências

Bailey, K. D. (1989). Taxonomy and disaster: Prospects and problems. International Journal of Mass Emergencies and Disasters, 7(3), 419-431.

Beck, U. (1996). Risk society: Towards a new modernity. London: SAGE Publications.

Douglas, M., \& Wildasky, A. (1982). Risk and Culture: an essay on the selection of technical and environmental dangers. Berkeley: University of California Press..

Drabeck, T. E. (1989). Disasters as non-routine social problems. International Journal of Mass Emergencies and Disasters, 7 (3), 253-264.

Giddens, A. (1991). As conseqüências da modernidade. São Paulo: Editora Universidade Estadual Paulista.

Hilgartner, S. (2007). Overflow and containment in the aftermath of disaster. Social Studies of Science, 37( 1), 153-158.

Kreps, G. A. (1984). Sociological inquiry and disaster research. Annual Review Sociology, 10, 309-330.
Kreps, G. A. (1989). Future directions in disasters research: The role of taxonomy. International of Mass Emergencies and Disasters, 7(3), 215-241.

Mattedi, M. A. (1999). As enchentes como tragédias anunciadas: impactos da problemática ambiental na situações de emergência em Santa Catarina. Campinas. Tese de Doutorado em Ciências Sociais, Universidade de Campinas, Campinas, SP.

United Nations Development Program. (2004). Reducing disaster risk: A challenge for development. New York: www. undp.org/bcpr.

Tobin, G. A., \& Montz, B.E. (1997). Natural hazards: Explanation and integration. New York: The Guilford Press.

Turner, R. H. (1989). Taxonomy as an approach to theory development? International Journal of Mass Emergencies and Disasters, 7(3), 265-275. 